MATEC Web of Conferences 15, 01027 (2014)

DOI: $10.1051 /$ matecconf/ 20141501027

(C) Owned by the authors, published by EDP Sciences, 2014

\title{
Implementation of Quality Management System for Historical Building Conservation
}

\author{
N.F. Zahari ${ }^{1}$, M.A. Bakar ${ }^{2}$, S.D.M. Wahid ${ }^{3}$, M.A.O Mydin ${ }^{4}$ \\ ${ }^{1,3}$ Universiti Teknologi MARA, Perak, 32610 Seri Iskandar, Malaysia \\ ${ }^{2}$ Universiti Teknologi MARA, 40450 Shah Alam, Selangor, Malaysia \\ ${ }^{4}$ School of Housing, Building and Planning, Universiti Sains Malaysia, 11800, Penang, Malaysia
}

\begin{abstract}
The main objectives of this study are twofold. Firstly, to identify the implementation of ISO 9001 procedures being used as references for conservation works and the development of Quality Management System (QMS) guidelines. Data were solicited from three (3) conservation areas. The analysis involved of descriptive approach and statistical methods. The findings revealed that QMS is not structurally established, implemented and enforced as part of conservation practice in Malaysia. From the findings, the authors hope to give clear perception to the reader on current preservation practice and the existence of QMS with reference to ISO 9001 for future conservation mechanism.
\end{abstract}

\section{Introduction}

Rapid development which in turns has some negative consequence effect on the old historical buildings contributes to the rising awareness on the need of conservation of these historical buildings with the main purpose of maintaining the buildings due to their historical, architectural and aesthetical values. In fact, the rising awareness on the importance of building conservation also is the reason on the endorsement of regulations such as National Heritage Act 2005 as well as other conservation guidelines. In addition to this, establishment of conservation bodies comprises of state authority, private societies, non-governmental organizations and charitable bodies also is a hard evidence that historical building conservation is not taken lightly within the local construction field. Similar to conservation, Quality Management is also a new field of which lately being practiced within the local construction industry. As conservation requires intricate monitoring in the control and assurance of maintaining the building to its original state, the implementation of ISO 9001 as a way to achieve the expected quality is seen as an important step in the conservation of historical building.

\section{Literature Review}

According to Darnall (1), Quality Management System (QMS) is a formal set of procedures and policies that defines how an organization will manage its potential impacts on the natural environment and on the health and welfare of the people who depend on it. Darnall (1) also states that it creates a system to access, catalogue and quantify facility quality impacts; not simply activity-by-activity, but 
throughout the entire organization. Main concept of QMS is voluntary in nature and at present, there is no requirement on enforcement of QMS. Developers and contractors who adopted QMS in their practices may seek certification of ISO 9001 from related agency like SIRIM. International Organization of Standardization (ISO) has been designed to help organization meeting their Quality Management System needs. ISO 9001 QMS is made up of 17 elements under five functional headings as shown in figure below.

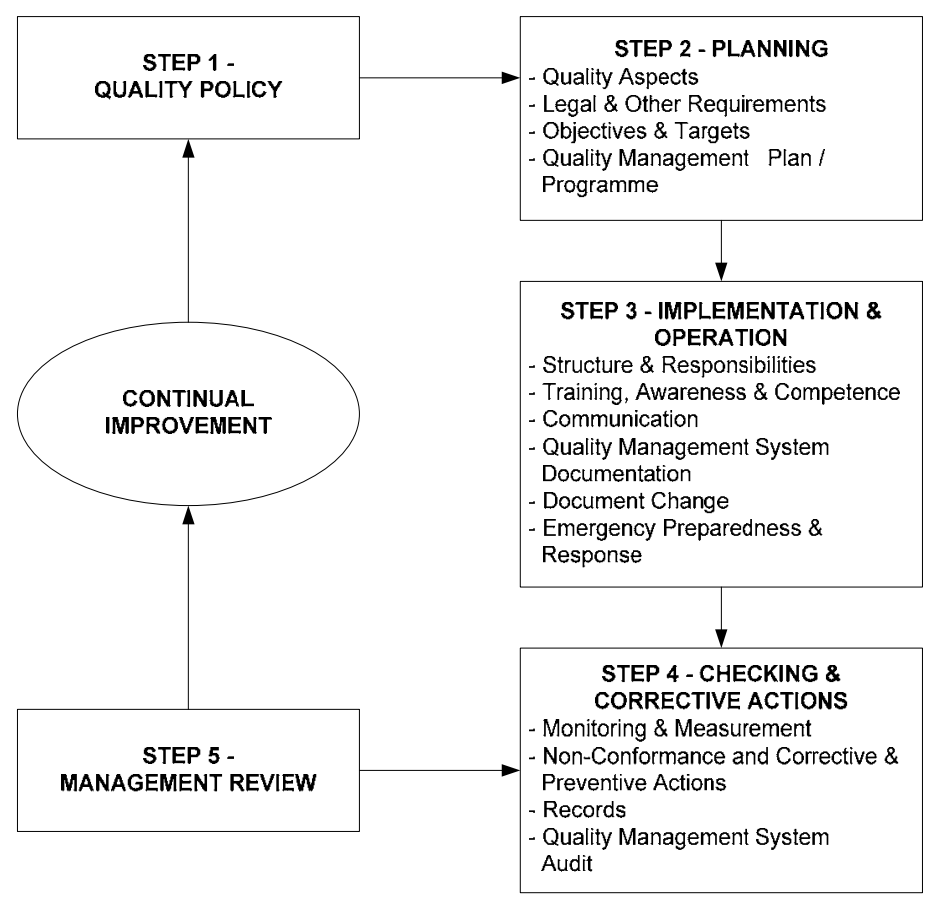

Figure 1: The 5 steps of ISO 9001 QMS.

\section{The Objectives}

The main objective is to identify the implementation of ISO 9001 which is a QMS implementation tool for conservation. The second objective is to determine the responses of the respondents on the implementation of QMS requirements for conservation projects.

\section{Methodology}

The research methodologies consist of a serial chronological process that requires a step-by-step approach; specifically designed in order to achieve the research objectives with the main concern of identifying the benefits of waste minimization in the aspect of cost, awareness and corporate image and others. 


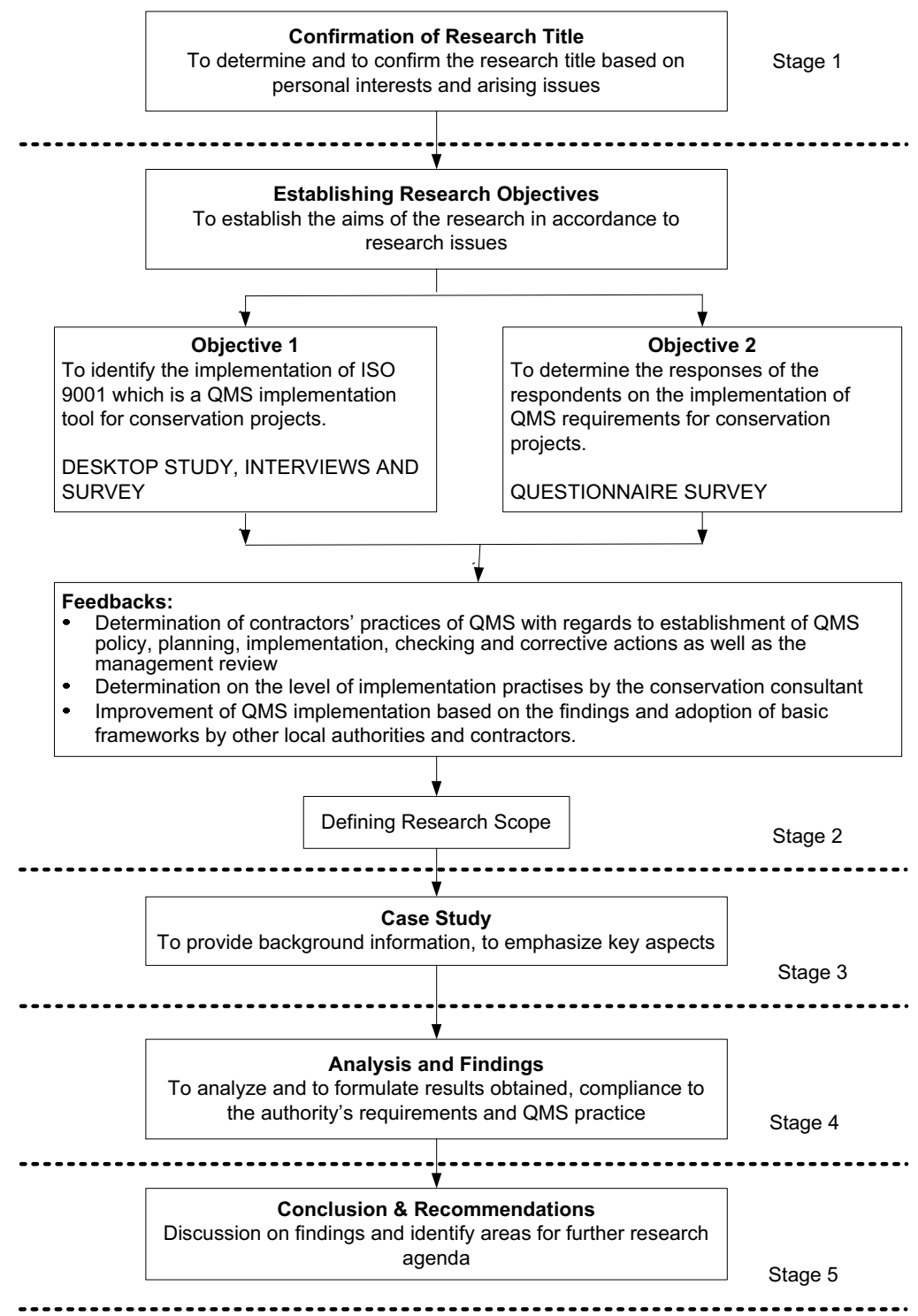

Figure 2: Research Methodological Model

\section{The Case Study}

The case study was conducted in three locations which are Blue Mansion, Penang, Studthuys, Malacca and Victoria Institute, Kuala Lumpur. All three case studies selected vary from administration office to mansion and commercial; Blue Mansion (museum/gallery), Stadhuys (museum) and Victoria Institution (theatrette). Conservation period for Blue Mansion is the longest among case studies which are 5 years while Stadhuys and Victoria Institution completed within 2 years. All projects were assisted by National Museum and Antiquities Department and other charitable organization and external conservation specialists appointed. Consultants and contractors involved in the projects were 
registered with the museum and have a good track record. QMS was not directly enforced or implemented using a standard quality tool or framework but it is a vital key in assuring the buildings were successfully conserved. The Antiquities Act, state legislation and authorities' requirements contribute much to the quality control and assessments.

\subsection{Blue Mansion, Penang}

Built on 56,000 square feet land and total built-up area 33,000 square feet, this mansion belong to Cheong Fatt Tze, a Chinese Official in Penang (Figure 1). Acted as base for his commercial enterprises and a home for the Chinese Vice-Consulate and his favoured $7^{\text {th }}$ wife. Ecletic architectural of Chinese and Colonial features, the mansion inclusive of two parts which are two side wings and the main hall is known as Hakka-Teochew mansion style. The mansion was bought by Penang Conservationists and restored after the death of his last son.

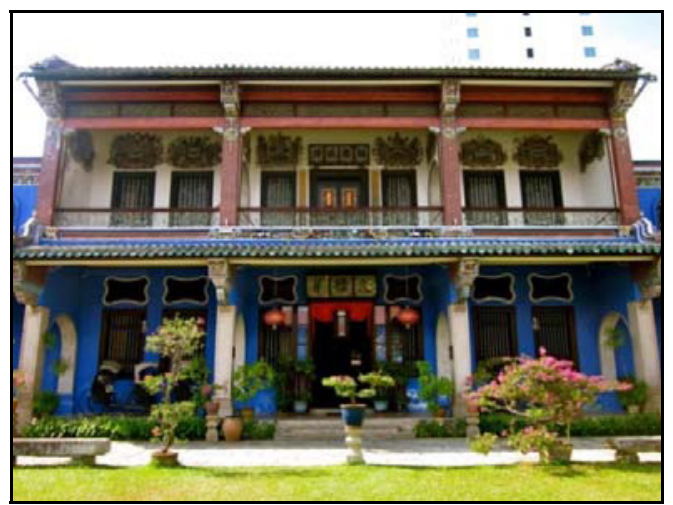

Figure 1: Front view of Blue Mansion, Penang.

\subsection{Stadthuys, Malacca}

One of the most historical building in Malaysia, Stadthuys (Figure 2) has been functioning as administrative center for three colonizer during colonization era; Portuguese, Dutch and English. After gaining independence, this building belongs to Malacca and functioning as the main office for Malacca Museum Department. Being a part of a complex built by the Portuguese, the building itself is a two-storey single unit with rectangular form with western architecture touch of Portuguese and Dutch influence.

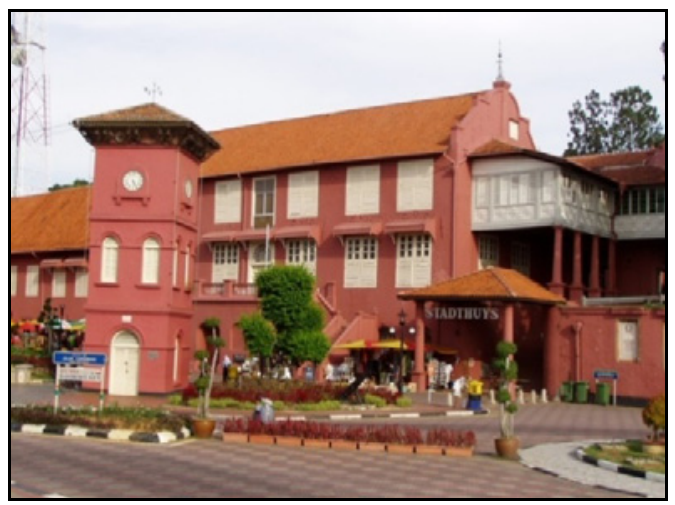

Figure 2 : Front view of Stadthuys, Malacca 


\subsection{Victoria Institute, Kuala Lumpur}

Former Victoria Institution now called the Kompleks Taman Budaya, Wilayah Persekutuan located in the center of Kuala Lumpur on the former Jalan Bandar was originally built in 1893 . The structure had been abandoned for several years and having deteriorated over time due to physical, environmental and fire impacts. Following the gazetment of the building under the Monument Act 1976 a contract was let to rebuild the structure in an adaptive reuse of a cultural heritage building to a modern auditorium for Arts. Besides the upgrading and conservation works, a new Annex building with a basement was included as part of development of the site.

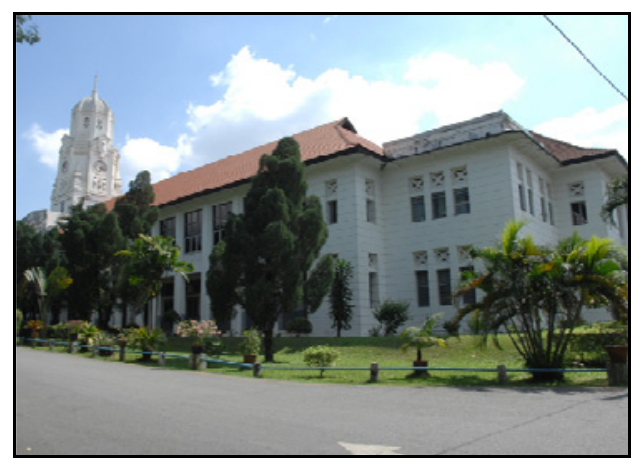

Figure 3: Victoria Institute

\section{Finding Analysis}

Generally, analysis of this research is divided into two sections; first section features comparative analysis on case studies with reference to the three numbers of conservation projects taken as case studies. The second section is the analysis on the questionnaire set distributed to 100 respondents.

\subsection{QMS implementation}

Table 1 shows the compliances to QMS requirements for the entire three conservation projects. ISO 9001 standard, which emphasizes the QMS requirements, was being used as the benchmark for the survey.

Table 1: Findings for conservation projects compliances to ISO 9001 standard.

\begin{tabular}{|c|c|c|c|c|}
\hline \multirow[b]{3}{*}{1.} & QMS Elements & \multicolumn{3}{|c|}{ Case Studies } \\
\hline & \multirow[b]{2}{*}{ Quality Policy } & Blue Mansion & Stadthuys & Victoria Institution \\
\hline & & $\mathbf{X}$ & $\mathbf{X}$ & $\mathbf{X}$ \\
\hline 2. & $\begin{array}{ll}\text { Planning } \\
\text { a. } & \text { Quality Aspects } \\
\text { b. } & \text { Legal and Other Requirements } \\
\text { c. } & \text { Objectives and Targets } \\
\text { d. } & \text { Quality Management Plan }\end{array}$ & $\begin{array}{l}\checkmark \\
\checkmark \\
\checkmark \\
\checkmark\end{array}$ & $\begin{array}{l}\checkmark \\
\checkmark \\
\checkmark \\
\checkmark\end{array}$ & $\begin{array}{l}\checkmark \\
\checkmark \\
\checkmark \\
\checkmark\end{array}$ \\
\hline 3. & $\begin{array}{ll}\text { Implementation and Operation } \\
\text { a. } & \text { Structure and Responsibilities } \\
\text { b. } & \text { Training, Awareness, and } \\
& \text { Competence } \\
\text { c. } & \text { Communication } \\
\text { d. } & \text { QMS Documentation } \\
\text { e. } & \text { Document Control } \\
\text { f. } & \text { Operational Control } \\
\text { g. } & \text { Emergency Preparedness and }\end{array}$ & $\begin{array}{c}X \\
\checkmark \\
\checkmark \\
\checkmark \\
X \\
\checkmark \\
\checkmark \\
\checkmark\end{array}$ & $\begin{array}{c}\text { X } \\
\checkmark \\
\checkmark \\
\checkmark \\
X \\
\checkmark \\
\checkmark \\
\checkmark\end{array}$ & $\begin{array}{c}X \\
\checkmark \\
\checkmark \\
\checkmark \\
X \\
\checkmark \\
\checkmark \\
\checkmark\end{array}$ \\
\hline
\end{tabular}




\begin{tabular}{|l|l|c|c|c|}
\hline & \multicolumn{1}{|c|}{ Response } & & & \\
\hline 4. & Checking and Corrective Action & & & $\checkmark$ \\
& a. Monitoring & $\checkmark$ & $\checkmark$ & $\checkmark$ \\
& b. Non-Conformance and Corrective & $\checkmark$ & $\checkmark$ & $\checkmark$ \\
& $\quad$ Action & $\checkmark$ & $\checkmark$ & $\checkmark$ \\
\hline & c. Records & $\checkmark$ & $\checkmark$ & $\checkmark$ \\
\hline $5 . \quad$ QMS Audit & Management Review & $\checkmark$ & $\checkmark$ & \\
\hline
\end{tabular}

\subsection{Analysis of Questionnaire}

The questionnaire is divided into two parts which are Section A-Respondents' Background and Section B-Implementation of QMS Requirements. For Section A, 100 respondents were randomly picked varies from conservation unit, local authorities, charitable bodies, private organization, consultants and contractors. Respondents involved in variety type of projects and can be concluded that the respondents have adequate working experience in their professional field.

For Section B, overall respondents also agreed that highlighting quality matters and checklists prepared specific to ISO 9001 framework are actions that need to be implement, submission of quality programme should be compulsory and assistance of authorities in preparation of all quality reports was necessary.

Table 2: Coding system for quality requirements with reference to Figure 3

\begin{tabular}{|c|l|}
\hline A & $\begin{array}{l}\text { Addressing compliance to the requirements by highlighting quality matters and preparing checklists } \\
\text { that related to specific quality regulations/acts }\end{array}$ \\
\hline B & Preparing and submitting all quality reports as per conservation stages and authority's requirements \\
\hline C & Assistance of Authorities for the preparation of all quality reports \\
\hline
\end{tabular}

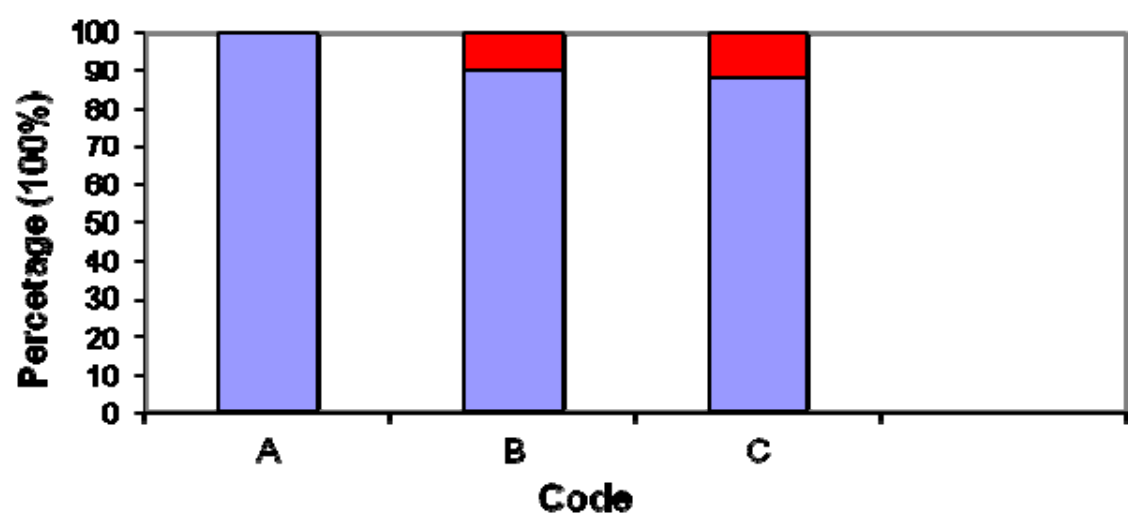

\section{口Agree $\quad$ aFair/Disagree}

Figure 3: Quality Control/Protection.

For QA/QC requirements, Conservation Council has prepared its own quality monitoring and testing standard for various aspects and the respondents claimed that they complied with the standard conservation requirement. 
Table 3: Coding system with reference to Figure 4.

\begin{tabular}{|c|l|}
\hline A & $\begin{array}{l}\text { All quality monitoring and testing are undertaken in accordance to the requirements' } \\
\text { specifications }\end{array}$ \\
\hline B & $\begin{array}{l}\text { All quality monitoring and testing are undertaken in accordance to the Conservation } \\
\text { standards }\end{array}$ \\
\hline C & Compliance of monitoring and testing results are checked by authorities' representatives \\
\hline D & Monitoring undertaken with the presence of authorities' representatives as witnesses \\
\hline
\end{tabular}

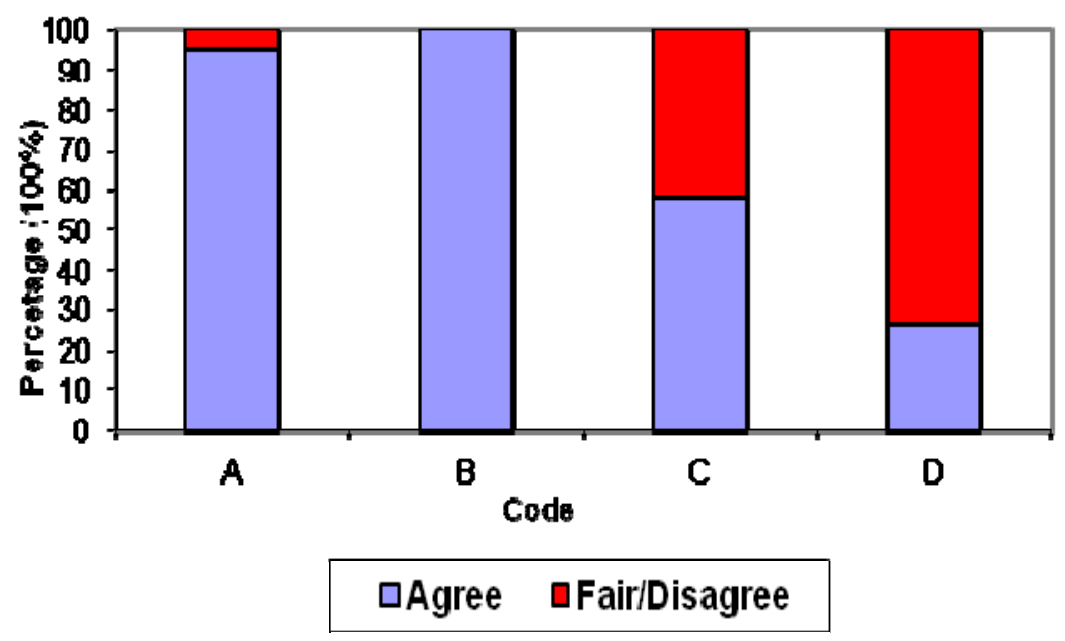

Figure 4: Compliance with Quality requirements.

Findings from analysis conducted confirmed that even though there is no specific QMS were implemented and enforced in conservation works; there was certain extent of quality related aspects that were required to be complied by the contractors and consultants. In terms of QMS implementation in Malaysia, majority of respondents had agreed on the idea of simultaneously implementing ISO 9001 as part of conservation management.

\section{Implication}

This research intends for contributing to significant practical implication of QMS in conservation work as it is important in maintaining the historical building. This study however only limited to the use of self- reported measures that may affect the responses by intentional distortions and misinformation.

\section{Conclusion}

It can be concluded that QMS is not implemented as part of the conservation programmes, plans and requirements. However, it was found that that a certain quality management standard was being applied for all conservation projects. However, as each project was undertaken at different state, none practice the same standardization and all developed their own quality measures or benchmarks. In determining the responses of the respondents on the implementation of QMS requirements for conservation projects, can be concluded that majority of the respondents agreed that the implementation of ISO 9001 may bring benefits to the conservation projects undertaken. In addition, the respondents viewed that there is a significant relationship for the implementation of ISO 9001 and conservation works. ISO 9001 is seen as an essential step to ensure that a standardized quality management can be practiced within the local context. 


\section{References}

1. ICOMOS; (Rev. 1999); the Australia ICOMOS Charter for The Conservation of Places of Cultural Significance (Burra Charter);

2. Government of Malaysia; (2005) National Heritage Act 2005 (Act 645); Laws of Malaysia; MDC Publishers printers Sdn Bhd.: Malaysia

3. Peter; J.L., (1996); Conservation and The City, Mcgraw hill Inc., London, United Kingdom 